\title{
Third-Order Nonlinear Optical Behavior of Novel Polythiophene Derivatives Functionalized with Disperse Red 19 Chromophore
}

\author{
Marilú Chávez-Castillo, ${ }^{1}$ Arelis Ledesma-Juárez, ${ }^{1}$ Marisol Güizado-Rodríguez, ${ }^{1}$ \\ Jesús Castrellón-Uribe, ${ }^{1}$ Gabriel Ramos-Ortiz, ${ }^{2}$ Mario Rodríguez, ${ }^{2}{ }$ José-Luis Maldonado, ${ }^{2}$ \\ Jorge-Antonio Guerrero-Álvarez, ${ }^{3}$ and Victor Barba ${ }^{3}$ \\ ${ }^{1}$ Centro de Investigación en Ingeniería y Ciencias Aplicadas (CIICAp), Universidad Autónoma del Estado de Morelos (UAEM), \\ Avenida Universidad No. 1001, Colonia Chamilpa, 62209 Cuernavaca, MOR, Mexico \\ ${ }^{2}$ Centro de Investigaciones en Óptica, A.P. 1-948, 37000 León, GTO, Mexico \\ ${ }^{3}$ Centro de Investigaciones Químicas (CIQ), Universidad Autónoma del Estado de Morelos (UAEM), Avenida Universidad No. 1001, \\ Colonia Chamilpa, 62209 Cuernavaca, MOR, Mexico
}

Correspondence should be addressed to Marisol Güizado-Rodríguez; marisolguizado@uaem.mx and Gabriel Ramos-Ortiz; garamoso@cio.mx

Received 5 November 2014; Accepted 12 March 2015

Academic Editor: Qijin Zhang

Copyright (C) 2015 Marilú Chávez-Castillo et al. This is an open access article distributed under the Creative Commons Attribution License, which permits unrestricted use, distribution, and reproduction in any medium, provided the original work is properly cited.

Two copolymers of 3-alkylthiophene (alkyl = hexyl, octyl) and a thiophene functionalized with disperse red 19 (TDR19) as chromophore side chain were synthesized by oxidative polymerization. The synthetic procedure was easy to perform, cost-effective, and highly versatile. The molecular structure, molecular weight distribution, film morphology, and optical and thermal properties of these polythiophene derivatives were determined by NMR, FT-IR, UV-Vis GPC, DSC-TGA, and AFM. The third-order nonlinear optical response of these materials was performed with nanosecond and femtosecond laser pulses by using the third-harmonic generation (THG) and Z-scan techniques at infrared wavelengths of 1300 and $800 \mathrm{~nm}$, respectively. From these experiments it was observed that although the TRD19 incorporation into the side chain of the copolymers was lower than 5\%, it was sufficient to increase their nonlinear response in solid state. For instance, the third-order nonlinear electric susceptibility $\left(\chi^{(3)}\right)$ of solid thin films made of these copolymers exhibited an increment of nearly $60 \%$ when TDR19 incorporation increased from $3 \%$ to $5 \%$. In solution, the copolymers exhibited similar two-photon absorption cross sections $\sigma_{2 \mathrm{PA}}$ with a maximum value of $8545 \mathrm{GM}$ and $233 \mathrm{GM}\left(1 \mathrm{GM}=10^{-50} \mathrm{~cm}^{4} \mathrm{~s}\right)$ per repeated monomeric unit.

\section{Introduction}

Synthesis, characterization, and applications of polythiophene (PT) derivatives are nowadays subjects of intense research [1-4]. PT derivatives have interesting physicochemical properties as good conductivity, nonlinear optical (NLO) response, photoluminescence (PL), high electrooptical activity, chemical and environmental stability, easy synthesis, and structural versatility. For these reasons, PT have been utilized in a broad spectrum of applications such as opticalchemical or electrochemical sensors [5, 6], organic solar cells $[3,7]$, optoelectronic devices for telecommunications and optical information processing [8], electro-optic modulators
[9], field-effect transistors [10], light-emitting diodes [11, 12], nanotechnology [13], and imaging labels in biological applications [14].

It is well known that the introduction of alkyl groups longer than butyl into the 3-position of the thiophene unit yields moderate to high molecular weight materials soluble in common organic solvents. The length of the alkyl side group affects melting point, solubility, and conductivity of the polymeric compound. Moreover, the presence of various substituents in 3- and/or 4-positions of the thiophene ring results in new materials which combine the physical properties of the polyconjugated backbone and the substituent group. For instance, a push-pull chromophore as a side group 
in the conjugated backbone enhanced charge-transfer properties and second-order NLO responses of a polythiophene [15-30]. The third-order NLO response in PT and other conjugated polymers has been also reported although less extensively in comparison with the second-order one, by using different techniques such as electroabsorption and $Z$ scan $[31,32]$.

In addition, azobenzene chromophores are a category of materials with very interesting chemical/optical properties [33]. They can exist in two isomeric forms (trans and cis), while the ratio of these two isomers can be modified by proper irradiation and detected through changes in their absorption spectra. Moreover, photoinduced birefringence, dichroism, and two-photon absorption processes can also take place in such systems. Because of its interesting properties the azobenzene is promising candidate for applications like optical data storage, surface relief gratings, photoswitching, alignment of liquid crystals, optical elements, and so forth $[34,35]$.

Among the wide range of azobenzene derivatives, dispersed red 1 (DR1) and dispersed red 19 (DR19) have been widely investigated because of their second-order and third-order nonlinear optical properties [36-40]. These azobenzene chromophores have been also utilized as side groups to combine their properties with those from polymers. For instance, a novel poly(urethane-imide) containing DR19 was synthesized obtaining excellent heat-resistance and a high third-order nonlinear property [41].

Herein, we report the oxidative polymerization and physic-chemical characterization of copolymers derived from 3-alkylthiophenes (alkyl = hexyl and octyl) and a thiophene monomer functionalized with DR19 chromophore. This NLO chromophore was attached to 3-thiopheneacetic acid by an esterification reaction. The photoluminescence properties were studied in solution with UV excitation $(365 \mathrm{~nm})$, while the third-order nonlinear optical response of these PT derivatives was evaluated with nanosecond and femtosecond laser pulses using THG Maker-fringes and $Z$ scan techniques at infrared wavelengths of 1300 and $800 \mathrm{~nm}$, respectively. A comparison of the nonlinearities exhibited by these novels PT and those measured in solution and solid state for other family of polymers recently reported is discussed.

\section{Experimental}

2.1. Materials and Equipment. Polymers syntheses were performed under nitrogen atmosphere, using conventional Schlenk techniques. Chloroform and nitromethane solvents were dried by distillation from $\mathrm{CaCl}_{2}$ or $\mathrm{MgSO}_{4}$ anhydrous. Compounds 3-hexylthiophene, 3-HT ( $\geq 99 \%)$ and 3octylthiophene, 3-OT (97\%), 3-thiopheneacetic acid (98\%), disperse red 19 (95\%), N,N'-dicyclohexylcarbodiimide (99\%), 4-(dimethylamino) pyridine $(\geq 98 \%)$, and iron (III) chloride (97\%) were purchased from Sigma-Aldrich. Solvents employed for the synthesis and purification process were obtained from Sigma-Aldrich and Fermont. NMR studies were carried out using a Varian Mercury $200 \mathrm{MHz}$ and Varian Inova $400 \mathrm{MHz}$ instruments. Polymers were dissolved in $\mathrm{CDCl}_{3}$ (ca. $5-10 \mathrm{mg}$ of polymer in $0.5 \mathrm{~mL}$ ) in $5 \mathrm{~mm}$ (o.d.) tubes and measured at $25^{\circ} \mathrm{C}$ with TMS as internal standard. Chemical shifts are stated in parts per million. IR spectra were obtained from Perkin Elmer Spectrum 400 spectrophotometer (ATR reflectance mode) in the $4000-400 \mathrm{~cm}^{-1}$ range. Mass spectra were recorded using a Mass Spectrometer High Resolution JMS700-JEOL. The molecular weights of the samples were measured by gel permeation chromatography (GPC, Alliance 2695; eluent, THF; temperature, $30^{\circ} \mathrm{C}$; injection volume, $25 \mu \mathrm{L} ; 2$ linear PLgel columns; UV detector) calibrated with 580 to 3,250,000 monodispersed polystyrene standards. Thermal stability measurements were carried out on a SDT Q600 V8.2 Build 100 thermogravimetric analyzer under a nitrogen flow (50 $\mathrm{mL} / \mathrm{min})$, mode: DSC-TGA Standard, with sapphire as calibration material and an alumina crucible. The equipment program used was Universal V4.2E. Absorption spectra were obtained with a spectrophotometer Perkin-Elmer Lambda $900 \mathrm{UV} / \mathrm{Vis} / \mathrm{NIR}$ with double beam. The photoluminescence spectra were recorded using a spectrometer (Ocean Optics, Dunedin, Florida, USA). The morphology of polymeric films was measured by AFM nanoscope IV multimode scanning probe microscope and nanosurf easy scope version 1.0.0.

\subsection{Synthesis of Monomer ((4-((4-Nitrophenyl)diazenyl)phe-} nyl)azanediyl)bis(ethane-2,1-diyl) Bis(2-(thiophen-3-yl)acetate), TDR19. In a flask ball, $0.88 \mathrm{~g}(6.06 \mathrm{mmol})$ of thiopheneacetic acid, $1.27 \mathrm{~g}$ (6.09 mmol) of dicyclohexylcarbodiimide (DCC), and $0.098 \mathrm{~g}(0.79 \mathrm{mmol})$ of dimethylamine pyridine (DMAP) were incorporated, after that $100 \mathrm{~mL}$ of dichloromethane was added. The reaction system was magnetically stirred and maintained under anhydrous conditions for $30 \mathrm{~min}$ to $25^{\circ} \mathrm{C}$. The mixture took on a light orange color, after a solution of $1.05 \mathrm{~g}(3.03 \mathrm{mmol})$ of red disperse 19 was added. The reaction was left under stirring for $24 \mathrm{~h}$. The product obtained was purified by the silica gel column chromatography using a mixture of 50/50 (hexane/ethyl acetate); the solutions were concentrated using a rotary evaporator under vacuum. This reaction gave the monomer TDR1. The product was a solid red color $0.56 \mathrm{~g}$, yield $=32.1 \%$. ${ }^{1} \mathrm{H} \mathrm{NMR}\left(\mathrm{CDCl}_{3}, 400 \mathrm{MHz}\right)$ : $\delta=8.32\left(\mathrm{~d}, 2 \mathrm{H}, \mathrm{H}_{20}\right), 7.92\left(\mathrm{~d}, 2 \mathrm{H}, \mathrm{H}_{19}\right), 7.89\left(\mathrm{~d}, 2 \mathrm{H}, \mathrm{H}_{14}\right)$, 7.27 (dd, $2 \mathrm{H}, \mathrm{H}_{5}$ ), $7.11\left(\mathrm{~m}, 2 \mathrm{H}, \mathrm{H}_{2}\right), 6.99\left(\mathrm{dd}, 2 \mathrm{H}, \mathrm{H}_{4}\right), 6.80$ (d, $2 \mathrm{H}, \mathrm{H}_{13}$ ), 4.29 (t, 4H, $\mathrm{H}_{9}$ ), 3.64 (s, 4H, H $\left.\mathrm{H}_{6}\right), 3.63$ (t, $4 \mathrm{H}$, $\left.\mathrm{H}_{10}\right) .{ }^{3} \mathrm{~J}\left(\mathrm{H}_{19-20}\right)=7.6 \mathrm{~Hz},{ }^{3} \mathrm{~J}\left(\mathrm{H}_{13-14}\right)=8.8 \mathrm{~Hz},{ }^{3} \mathrm{~J}\left(\mathrm{H}_{4-5}\right)=$ $5.0 \mathrm{~Hz},{ }^{3} \mathrm{~J}\left(\mathrm{H}_{9-10}\right)=6.0 \mathrm{~Hz} .{ }^{13} \mathrm{C} \mathrm{NMR}\left(\mathrm{CDCl}_{3}, 400 \mathrm{MHz}\right): \delta$ $=171.1\left(\mathrm{C}_{7}\right), 156.8\left(\mathrm{C}_{18}\right), 151.1\left(\mathrm{C}_{12}\right), 147.9\left(\mathrm{C}_{21}\right), 144.5\left(\mathrm{C}_{15}\right)$, $133.3\left(\mathrm{C}_{3}\right), 128.6\left(\mathrm{C}_{4}\right), 126.3\left(\mathrm{C}_{14}\right), 126.2\left(\mathrm{C}_{5}\right), 124.9\left(\mathrm{C}_{20}\right)$, $123.3\left(\mathrm{C}_{2}\right), 123.0\left(\mathrm{C}_{19}\right), 111.9\left(\mathrm{C}_{13}\right), 62.8\left(\mathrm{C}_{9}\right), 49.6\left(\mathrm{C}_{10}\right)$, $35.9\left(\mathrm{C}_{6}\right)$. FT-IR $\left(\nu \mathrm{cm}^{-1}\right): \mathrm{C}_{-\mathrm{H}_{\mathrm{st}}}\left(2920 \mathrm{~cm}^{-1}, 2852 \mathrm{~cm}^{-1}\right)$, $\mathrm{C}=\mathrm{O}_{\mathrm{st}}\left(1731 \mathrm{~cm}^{-1}\right), \mathrm{C}=\mathrm{C}_{\mathrm{st}}\left(1599 \mathrm{~cm}^{-1}\right), \mathrm{NO}_{2 \mathrm{st} \mathrm{as}}\left(1512 \mathrm{~cm}^{-1}\right)$, $\mathrm{NO}_{2 \text { st sym }}\left(1331 \mathrm{~cm}^{-1}\right), \mathrm{C}-\mathrm{O}_{\text {st }}\left(1128 \mathrm{~cm}^{-1}\right), \mathrm{C}-\mathrm{S}_{\mathrm{st}}\left(723 \mathrm{~cm}^{-1}\right.$, $\left.684 \mathrm{~cm}^{-1}\right)$. MS $(\mathrm{m} / z)=578\left[\mathrm{M}^{+}\right] 579\left[\mathrm{M}^{+1}\right]$. Mass spectroscopy high resolution, $(\mathrm{m} / z)=579.1377$ corresponding to $\mathrm{C}_{28} \mathrm{H}_{27} \mathrm{~N}_{4} \mathrm{O}_{6} \mathrm{~S}_{2}$. 


\subsection{Synthesis of Copolymers}

2.3.1. Synthesis of Copolymer of 3-Hexylthiophene (3-HT) and TDR19, P1. In a typical preparation, a solution containing $2.91 \mathrm{~g}(17.40 \mathrm{mmol})$ of $\mathrm{FeCl}_{3}$ in $40 \mathrm{~mL}$ of chloroform and $10 \mathrm{~mL}$ of nitromethane was placed into the reactor cooled to $0^{\circ} \mathrm{C}$. Then, a solution of $1.30 \mathrm{~g}(2.24 \mathrm{mmol})$ of monomer TDR19 in $20 \mathrm{~mL}$ of chloroform was added in one portion. In the next step a solution of $1.08 \mathrm{~g}, 1.14 \mathrm{~mL}(6.35 \mathrm{mmol})$ of 3-hexylthiophene in $40 \mathrm{~mL}$ chloroform was added dropwise. The polymerization was left at room temperature with constant stirring and was terminated by addition of $200 \mathrm{~mL}$ of methanol. The precipitated polymer was then separated and washed repeatedly with methanol. Since the crude polymer is partially doped, it was treated with a mixture of $\mathrm{NH}_{3}$ (aq)/MeOH, $200 \mathrm{~mL}$ for $1 \mathrm{~h}$ order to remove the excess of $\mathrm{FeCl}_{3}$. The neutral polymer was purified with chloroform in a soxhlet apparatus and dried to constant mass, obtaining $0.86 \mathrm{~g}(22 \%)$ of a soluble part and $1.47 \mathrm{~g}(38 \%)$ of insoluble material. ${ }^{1} \mathrm{H}$ NMR (400 MHz, $\mathrm{CDCl}_{3}$ ), 3-HT signals: $\delta=6.98$ $\left(\mathrm{H}_{4^{\prime}}\right), 2.56,2.80\left(\mathrm{H}_{\alpha}\right), 0.91-1.69\left(\mathrm{H}_{\text {aliphatic }}\right)$. TDR19 signals: $\delta=8.30\left(\mathrm{H}_{20}\right), 7.87\left(\mathrm{H}_{19}\right), 7.80\left(\mathrm{H}_{14}\right), 6.98\left(\mathrm{H}_{4}\right), 6.75\left(\mathrm{H}_{13}\right)$, $4.37\left(\mathrm{H}_{9}\right), 3.69\left(\mathrm{H}_{6}, \mathrm{H}_{10}\right)$. FT-IR $\left(\nu \mathrm{cm}^{-1}\right): \mathrm{C}-\mathrm{H}_{\mathrm{st}}(2920$, $\left.2860 \mathrm{~cm}^{-1}\right), \mathrm{C}=\mathrm{O}_{\text {st }}\left(1738 \mathrm{~cm}^{-1}\right), \mathrm{C}=\mathrm{C}_{\mathrm{st}}\left(1599 \mathrm{~cm}^{-1}\right), \mathrm{N}=\mathrm{N}_{\mathrm{st}}$ $\left(1512 \mathrm{~cm}^{-1}\right), \mathrm{NO}_{2 \text { st as }}\left(1460 \mathrm{~cm}^{-1}\right), \mathrm{NO}_{2 \text { st sym }}\left(1333 \mathrm{~cm}^{-1}\right), \mathrm{C}-$ $\mathrm{O}_{\text {st }}\left(1100 \mathrm{~cm}^{-1}\right), \mathrm{C}-\mathrm{S}_{\mathrm{st}}\left(706 \mathrm{~cm}^{-1}\right)$.

2.3.2. Synthesis of Copolymer of 3-Octylthiophene (3-OT) and TDR19, P2. This copolymer was synthesized using the same synthetic procedure as for P1. A solution containing $5.34 \mathrm{~g}$ $(31.69 \mathrm{mmol})$ of $\mathrm{FeCl}_{3}$ in $70 \mathrm{~mL}$ of chloroform and $20 \mathrm{~mL}$ of nitromethane was placed into the reactor cooled to $0^{\circ} \mathrm{C}$. Then a solution of $0.50 \mathrm{~g}(0.86 \mathrm{mmol})$ of monomer TDR19 in $20 \mathrm{~mL}$ of chloroform was added in one portion. Later, a solution of $1.40 \mathrm{~g}, 1.52 \mathrm{~mL}$ (6.92 mmol) of 3-octylthiophene in $40 \mathrm{~mL}$ chloroform was added dropwise. The polymerization was left at room temperature with constant stirring for $24 \mathrm{~h}$ and was purified in the same manner as the above procedure, obtaining $0.23 \mathrm{~g}(10 \%)$ of a soluble part and $1.22 \mathrm{~g}(43 \%)$ of insoluble copolymer. ${ }^{1} \mathrm{H}$ NMR $\left(200 \mathrm{MHz} \mathrm{CDCl}_{3}\right), 3-\mathrm{OT}$ signals: $\delta=6.98,6.95,6.93,6.91\left(\mathrm{H}_{4^{\prime}}\right), 2.48,2.72\left(\mathrm{H}_{\alpha}\right), 0.80-$ $1.62\left(\mathrm{H}_{\text {aliphatic }}\right)$. TDR19 signals: $\delta=8.26\left(\mathrm{H}_{20}\right), 7.86\left(\mathrm{H}_{19}\right), 7.83$ $\left(\mathrm{H}_{14}\right), 6.80\left(\mathrm{H}_{4}\right), 6.70\left(\mathrm{H}_{13}\right), 4.30\left(\mathrm{H}_{9}\right), 3.60\left(\mathrm{H}_{6}, \mathrm{H}_{10}\right)$. FT-IR $\nu\left(\mathrm{cm}^{-1}\right): \mathrm{C}_{-} \mathrm{H}_{\mathrm{st}}\left(2954,2921,2852 \mathrm{~cm}^{-1}\right), \mathrm{C}=\mathrm{O}_{\mathrm{st}}\left(1740 \mathrm{~cm}^{-1}\right)$, $\mathrm{C}=\mathrm{C}_{\mathrm{st}}\left(1652 \mathrm{~cm}^{-1}\right), \mathrm{N}=\mathrm{N}_{\mathrm{st}}\left(1511 \mathrm{~cm}^{-1}\right), \mathrm{NO}_{2 \mathrm{st} \text { as }}\left(1456 \mathrm{~cm}^{-1}\right)$, $\mathrm{NO}_{2 \text { st sym }}\left(1339 \mathrm{~cm}^{-1}\right), \mathrm{C}-\mathrm{O}_{\text {st }}\left(1138 \mathrm{~cm}^{-1}\right), \mathrm{C}-\mathrm{S}_{\text {st }}\left(721 \mathrm{~cm}^{-1}\right)$.

Chemical structures of P1 and P2 are shown in Figure 1.

2.4. Third-Harmonic Generation (THG) Experiment. Cubic nonlinearities were studied in solid state (solid films). Polymers were dissolved in tetrahydrofuran and thin films were then deposited on fused silica substrates ( $1 \mathrm{~mm}$ thick) by using the spin coating technique. Films with good optical quality showing negligible light scattering at visible and NIR wavelengths were obtained with thickness of $283 \mathrm{~nm}$ for P1 and $405 \mathrm{~nm}$ for P2.

The THG Maker-fringes technique was used to characterize the optical nonlinearities of thin films. The experimental setup consisted of an optical parametric oscillator (OPO) pumped by a Nd-YAG laser that delivered pulses of $8 \mathrm{~ns}$ with a repetition rate of $10 \mathrm{~Hz}$. The $\mathrm{OPO}$ was tuned at $1300 \mathrm{~nm}$. The laser beam was focused into the films with a $30 \mathrm{~cm}$ focallength lens to form a spot with a radius of approximately $150 \mu \mathrm{m}$. Typical energies in our measurements were set at $3 \mathrm{~mJ}$ per pulse at sample position. The third-harmonic beam, as a bulk effect, emerging from the films was separated from the pump beam by using a color filter and detected with a PMT and a Lock-in amplifier. The THG measurements were performed for incident angles in the range from $-40^{\circ}$ to $40^{\circ}$ with steps of $0.27^{\circ}$.

In the Maker-fringes technique, the third-harmonic peak intensity $I^{3 \omega}$ from the substrate-film structure is compared to one produced from the substrate alone. Then the nonlinear susceptibility $\chi^{(3)}$ in a film of thickness $L_{f}$ is determined from

$$
\chi^{(3)}=\chi_{s}^{(3)} \frac{2}{\pi} L_{c, s}\left(\frac{\alpha / 2}{1-\exp \left(\alpha L_{f} / 2\right)}\right)\left(\frac{I_{f}^{3 \omega}}{I_{s}^{3 \omega}}\right)^{1 / 2},
$$

where $\chi_{s}^{(3)}$ and $L_{c, s}$ are the nonlinear susceptibility and coherence length, respectively, for the substrate at the fundamental wavelength, and $\alpha$ is the film absorption coefficient at the harmonic wavelength. In our calculation we considered $\chi_{s}^{(3)}=3.1 \times 10^{-14}$ esu for the fused silica substrate and $L_{c, s}(12 \mu \mathrm{m}$ at $1300 \mathrm{~nm})$ was calculated from tabulated values of the refractive index. Our samples satisfied the condition $L_{f} \ll L_{c, s}$ in which (1) is valid.

2.5. Z-Scan. Cubic nonlinearities were also studied in solution. In this case we performed nonlinear absorption characterization by means of an open-aperture $Z$-scan set-up. Briefly, a femtosecond Ti:sapphire regenerative amplifier delivered pulses of $80 \mathrm{fs}(1 \mathrm{kHz}$ repetition rate) at $800 \mathrm{~nm}$. These laser pulses were focused into a beam waist radius of $20 \mu \mathrm{m}$. Chloroform solution $\left(3 \times 10^{-3} \mathrm{M}\right)$ of our PT was poured in $1 \mathrm{~mm}$ thick quartz cell and tested in the $Z$-scan set-up. To avoid sample degradation, the peak irradiance was kept below $60 \mathrm{GW} / \mathrm{cm}^{2}$. The nonlinear absorption coefficient $\beta$ was obtained using the following relations [45]:

$$
T(Z)=1+\frac{1}{2 \sqrt{2}} \beta \frac{I_{0} L_{\mathrm{eff}}}{1+\left(Z / Z_{0}\right)^{2}} .
$$

Here $T(z)$ is the normalized transmittance of the sample scanned along the $Z$-axis of a focused beam detected at a far-field position, $I_{0}$ is the light peak intensity at the beam waist, and $Z_{0}$ is the Rayleigh distance. Thus, the two-photon absorption cross section can be evaluated from $\sigma_{2 \mathrm{PA}}=$ $(\hbar \omega / N) \beta$, where $\hbar \omega$ is the photon energy and $N$ is the density of molecules in the sample. To verify the validity of the measurements, the $Z$-scan set-up was previously calibrated with the standard $\mathrm{CS}_{2}$.

\section{Results and Discussion}

Spectroscopic NMR results showed that for both copolymers the incorporation of TDR19 was no higher than 5\% (P1 > P2); 


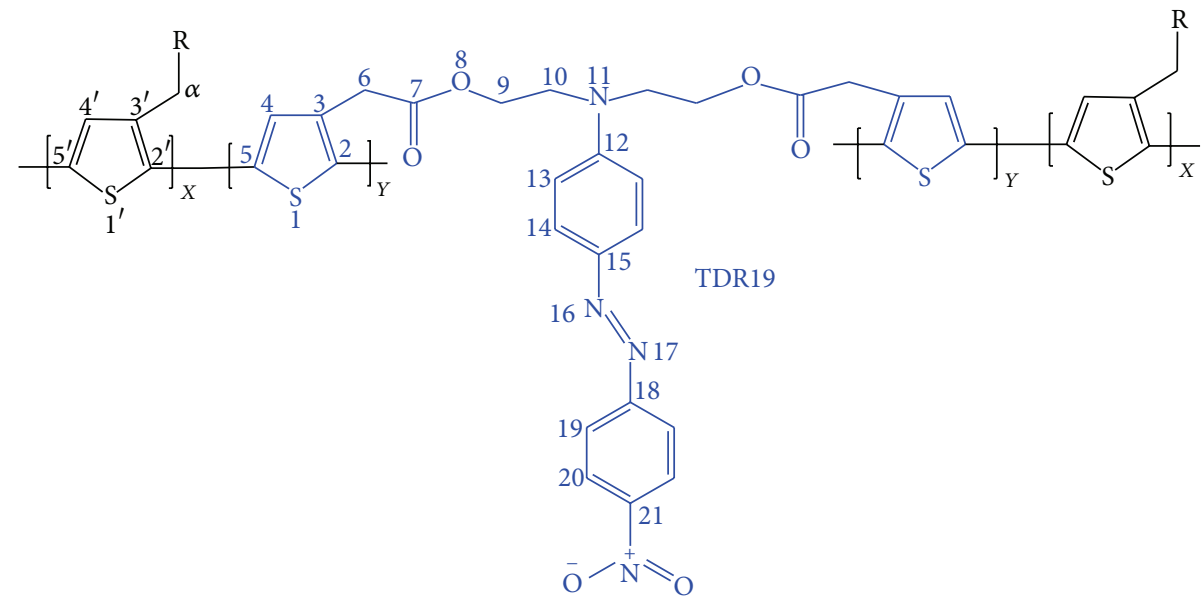

$\mathrm{R}=\mathrm{C}_{5} \mathrm{H}_{11}, \mathrm{P} 1$

$\mathrm{R}=\mathrm{C}_{7} \mathrm{H}_{15}, \mathrm{P} 2$

Figure 1: Structure of copolymers P1 and P2.

TABle 1: Polymers characteristics.

\begin{tabular}{|c|c|c|c|c|c|c|c|c|c|c|c|c|c|}
\hline \multirow{3}{*}{ Polymers } & \multirow{3}{*}{$\begin{array}{c}\text { Monomer } \\
\text { ratio }^{\mathrm{a}}\end{array}$} & \multicolumn{3}{|c|}{ Molecular weight } & \multicolumn{3}{|c|}{ Thermal stability } & \multicolumn{6}{|c|}{ Configuration } \\
\hline & & \multirow[b]{2}{*}{$\overline{\mathrm{Mn}}$} & \multirow[b]{2}{*}{$\overline{\mathrm{Mw}}$} & \multirow[b]{2}{*}{ PDI } & \multirow[b]{2}{*}{$T_{d}\left({ }^{\circ} \mathrm{C}\right)$} & \multirow[b]{2}{*}{$T_{g}\left({ }^{\circ} \mathrm{C}\right)$} & \multirow[b]{2}{*}{ Weight loss (\%) } & \multicolumn{2}{|c|}{ Diads (\%) } & \multicolumn{4}{|c|}{ Triads (\%) } \\
\hline & & & & & & & & HT & $\mathrm{HH}$ & HT-HT & TT-HT & HT-HH & TT-HH \\
\hline P1 & $95: 5$ & 6908 & 26553 & 3.8 & 480 & 155 & 67.2 & 74 & 26 & 63 & 13 & 14 & 10 \\
\hline $\mathrm{P} 2$ & $97: 3$ & 7406 & 21996 & 2.9 & 476 & 147 & 69.3 & 76 & 24 & 60 & 16 & 13 & 11 \\
\hline
\end{tabular}

${ }^{a}$ Relation between monomers incorporated into the polymer, 3-alkylthiophene (alkyl = hexyl or octyl)/functionalized thiophene.

this is in accordance with the molar feed ratio used in the synthesis of the copolymers (relation 1:0.35 (3-HT: TDR19) for P1 and relation 1:0.12 (3-OT:TDR19) for P2). This difference was sufficient to increase the nonlinear properties of the polymers in solid state. The regioregularity (diads and triads) molecular weight distribution ( $\mathrm{Mn}$ and $\mathrm{Mw}$ ) and thermal properties $\left(T_{d}\right.$ and $\left.T_{g}\right)$ are similar with those normally found in PT synthesized according to the same regioselective method [15-30]. These values were also similar between both copolymers; only the copolymer obtained from 3-HT showed a higher polydispersity consistent with the presence of a greater amount of TDR19 in the copolymer P1. These physicochemical properties are summarized in Table 1.

3.1. Linear Optical Properties. UV-Vis absorption spectra for PT (P1 and P2) and the monomer were measured in THF solutions $(0.1 \mathrm{mg} / \mathrm{mL})$. Both P1 and P2 exhibit wavelengths of maximum absorbance $\left(\lambda_{\max }\right)$ around $430 \mathrm{~nm}$, whereas the maximum of absorption for the monomer TDR19 appears at $460 \mathrm{~nm}$ (Figure 2(a)). The more intense absorption of P1 and P2 with respect to TDR19 could be due to the more extended $\pi$-conjugated backbones of the polymers that are related with the regioregularity of HT dyads. In addition, it has been found that while the length of alkyl chain in 3 -alkylthiophene copolymers is shorter, their absorbance is higher [21]. The fact that the monomer exhibits maximum absorption at the longest wavelength reflects the highest charge-transfer interaction occurring between the electrondonor group (amino) and the electron-acceptor group (nitro) of TDR19 [36]. The photoluminescence (PL) spectra showed an emission band of P1 and P2 at $567 \mathrm{~nm}$ with a small shoulder at $610 \mathrm{~nm}$ (Figure 2(b)) when copolymers were irradiated at $365 \mathrm{~nm}$ (UV). Both copolymers have stokes shifts around $5500 \mathrm{~cm}^{-1}$ and P1 has slightly higher emission than P2. The monomer TDR19 has an emission band around $552 \mathrm{~nm}$ with stokes shift of $3623 \mathrm{~cm}^{-1}$. The relatively low incorporation of this monomer into the copolymers is evident since its presence is not significantly affecting their $\lambda_{\text {max }}$ in the absorption and emission spectra; however, this difference can be seen in the higher absorption of P1 regarding P2.

Moreover, the PL characteristics of P1 and P2 in toluene were measured at different concentrations: diluted solutions, from $0.005 \mathrm{mg} / \mathrm{mL}$ to $0.025 \mathrm{mg} / \mathrm{mL}$ (Figures 3(a) and 4(a)), and concentrated solutions, from $0.5 \mathrm{mg} / \mathrm{mL}$ to $2.5 \mathrm{mg} / \mathrm{mL}$ (Figures 3(b) and 4(b)). These measurements were obtained when the copolymer was excited at $365 \mathrm{~nm}$ (UV). In diluted solutions, the maximum photoluminescence $\left(\lambda_{\max }^{\mathrm{PL}}\right)$ was measured at $573 \mathrm{~nm}$ and $570 \mathrm{~nm}$ for P1 and P2, respectively, with a shoulder at $607 \mathrm{~nm}$ in both cases. In concentrated solutions, for both PT copolymers the peak of maximum PL decreases considerably with respect to the shoulder at the time that $\lambda_{\max }^{\mathrm{PL}}$ was red-shifted approximately $15 \mathrm{~nm}$ while the shoulder was red-shifted only $4 \mathrm{~nm}$. Additional peaks that are observed in the spectra of PT are usually associated with $\pi \rightarrow \pi^{*}$ 


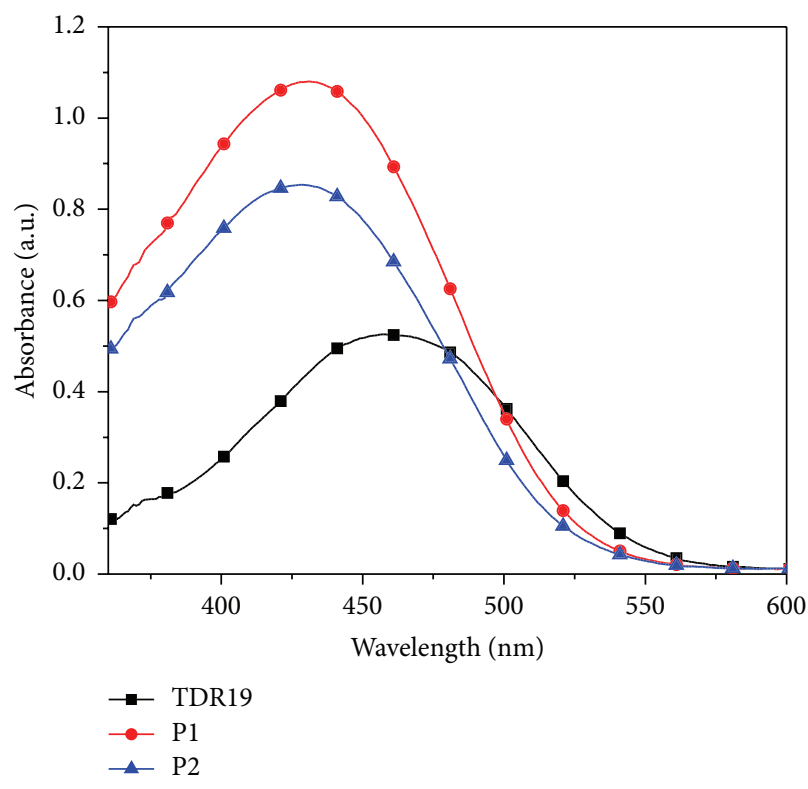

(a)

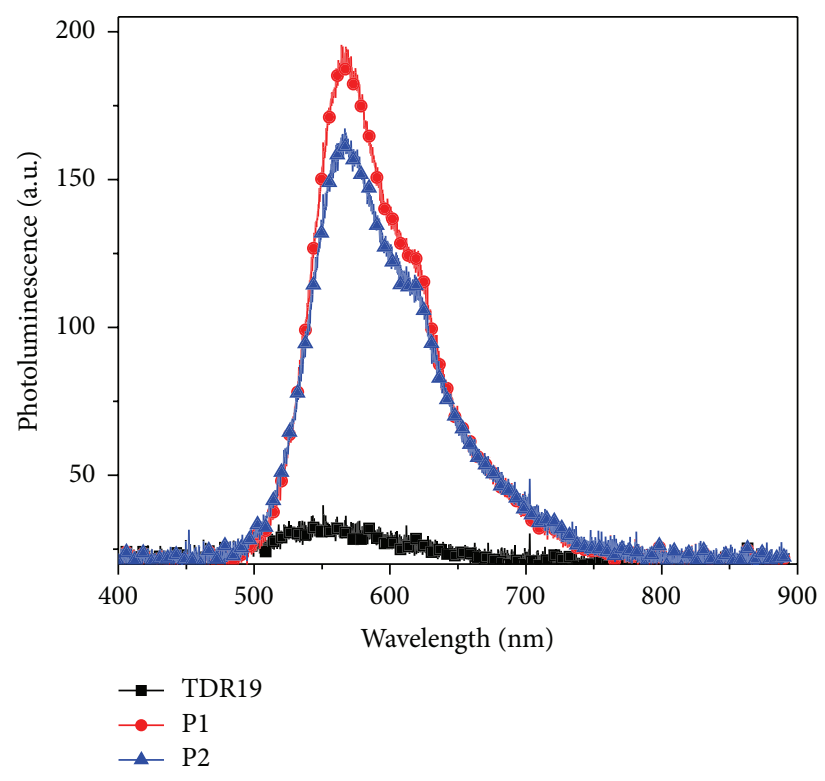

(b)

Figure 2: (a) Absorption and (b) emission spectra of solutions ( $0.1 \mathrm{mg} / \mathrm{mL})$ in THF of monomer TDR19 and copolymers P1 and P2.

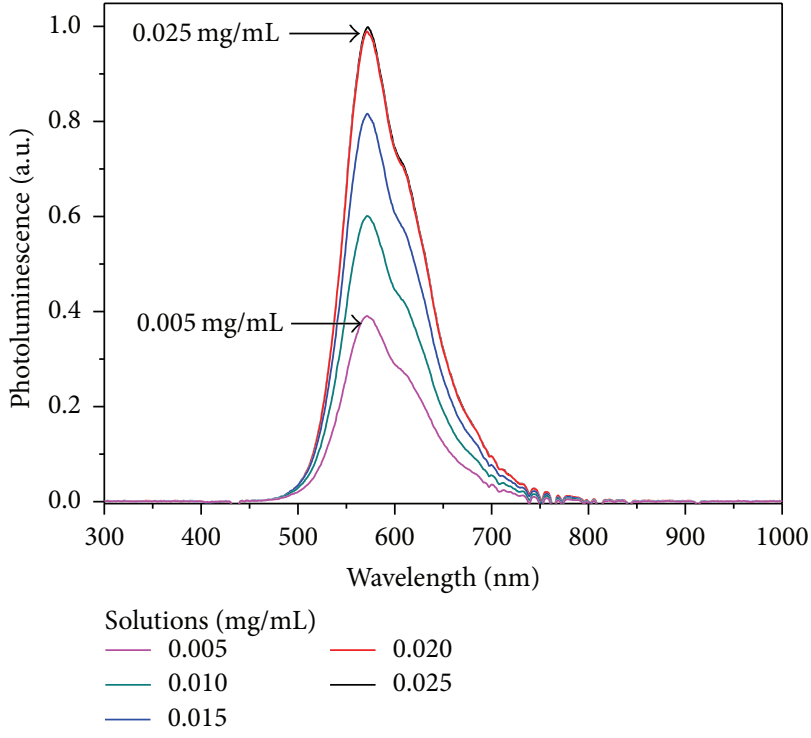

(a)

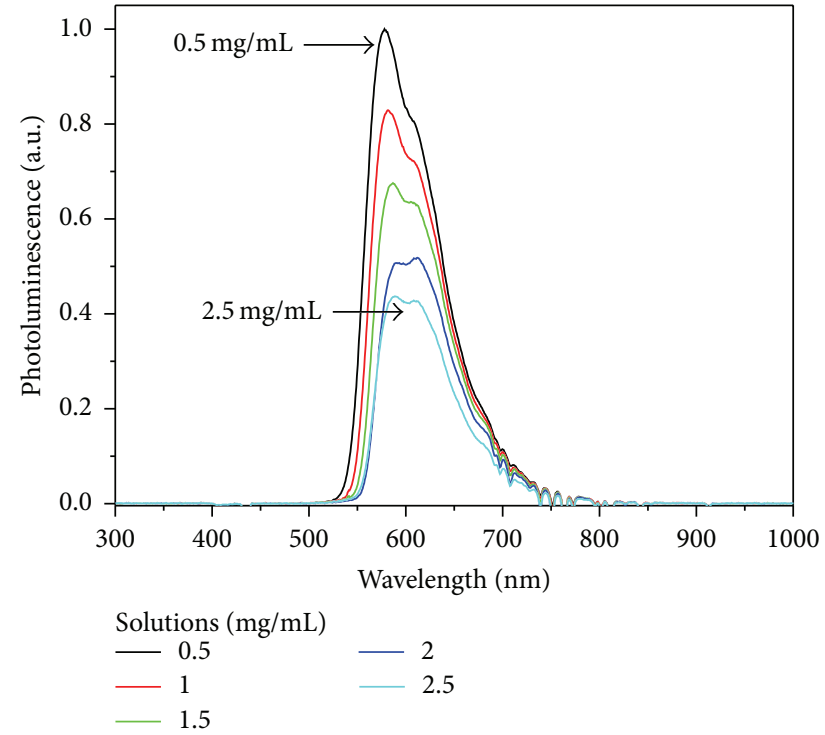

(b)

FIGURE 3: PL spectra of the copolymer P1, (a) diluted and (b) concentrated toluene solutions under UV excitation at $365 \mathrm{~nm}$.

interchain transitions in the stacked thiophene rings, which result in the lowered energy excited states [32].

In dilute solutions, the intensity of emission increases with the concentration while in concentrated solutions a PL quenching effect is observed. The change in shape of the bands and PL quenching in solutions of high concentrations is associated with exciton quenching effects observed typically in PT, in which direct photogeneration of polaron pairs instead of neutral excitons takes place or low energy charge transfer state related to $\mathrm{H}$-aggregate geometry is present $[46$,
47]. However, the behavior of PT in films is controversial; it is proposed that some interpolymer interactions and structural disorder drastically affect the optical and electronic properties, as light absorption and fluorescing states, mechanisms of exciton quenching, and energy and charge transfer [12].

It is important to discuss also the film conformation for $\mathrm{P} 1$ and $\mathrm{P} 2$, since this issue can determine its optical properties (linear and nonlinear). Morphologic analysis of polymeric films was done by using AFM; films $(50 \mathrm{mg} / \mathrm{mL}$ in toluene) were prepared by drop casting technique. These 


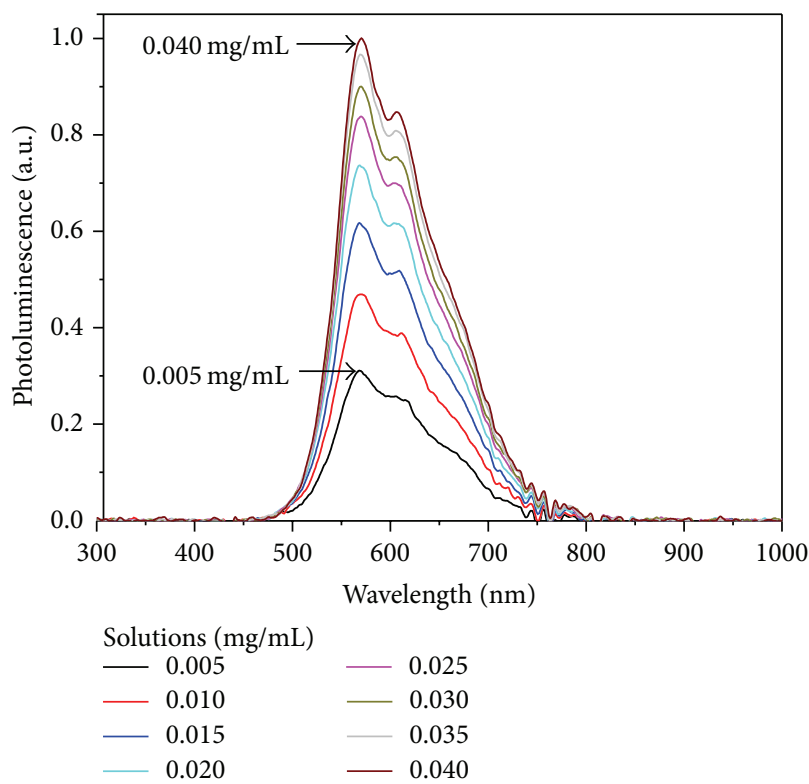

(a)

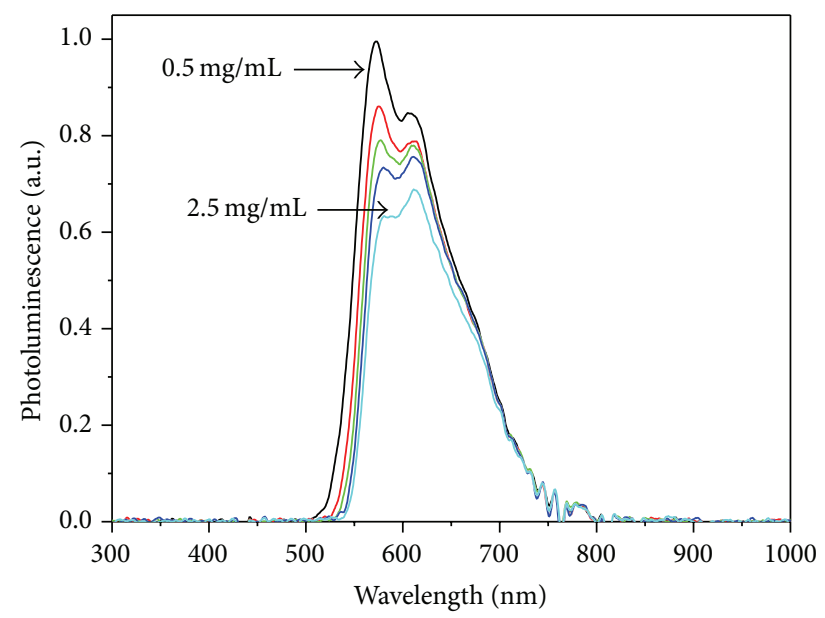

Solutions $(\mathrm{mg} / \mathrm{mL})$

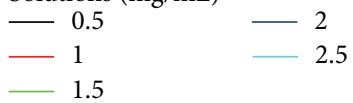

(b)

FIgURE 4: PL spectra of the copolymer P2, (a) diluted and (b) concentrated toluene solutions under UV excitation (365 nm).

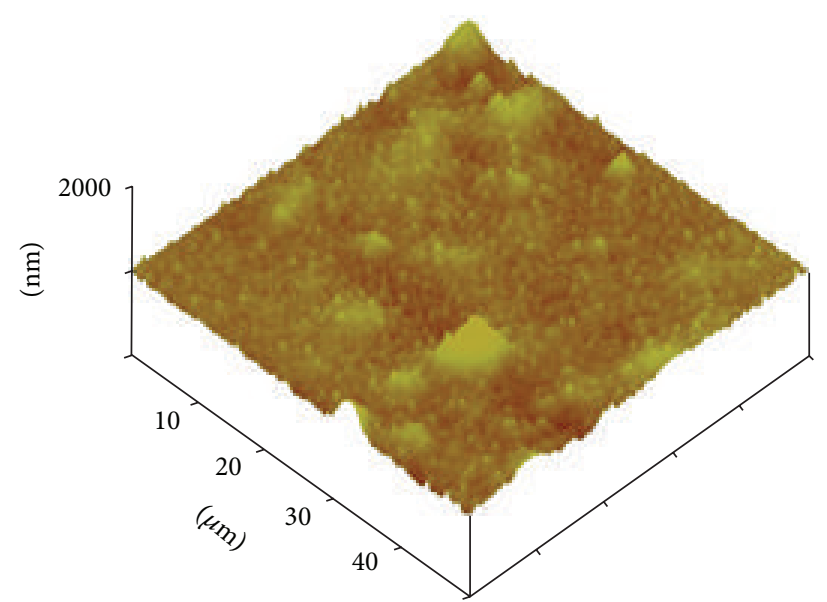

(a)

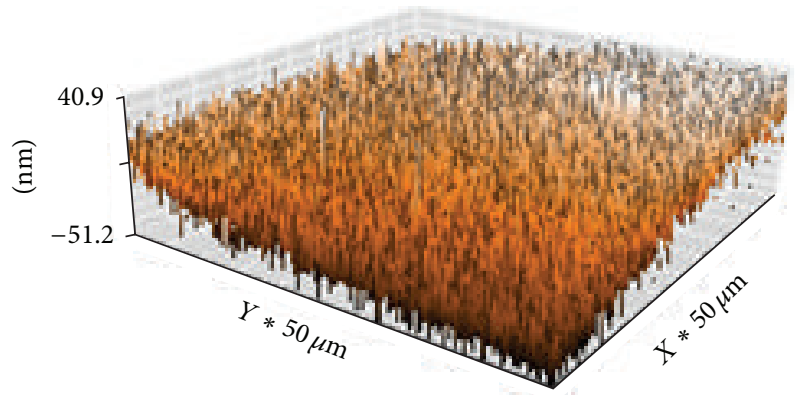

$\left(\mathrm{a}^{\prime}\right)$

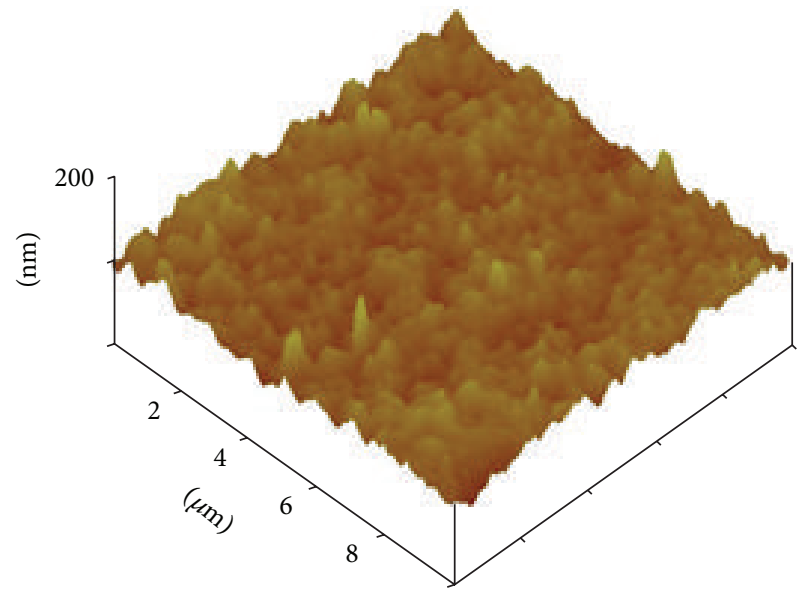

(b)

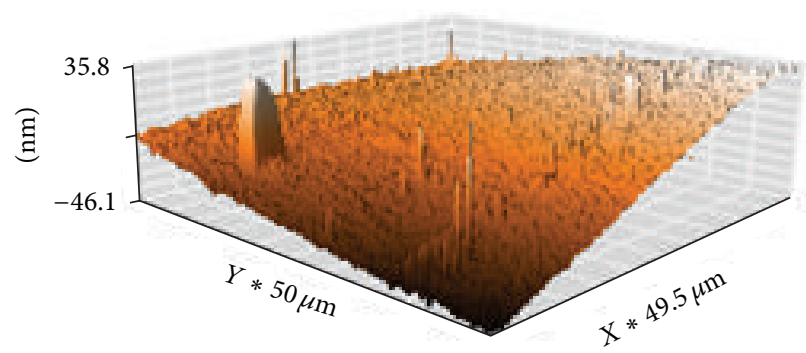

$\left(\mathrm{b}^{\prime}\right)$

FIgURE 5: AFM micrographs of film copolymers (a) P1 and (b) P2 fabricated by drop casting from toluene solutions and ( $\mathrm{a}^{\prime}$ ) P1 and ( $\mathrm{b}^{\prime}$ ) P2 prepared by spin coating from chloroform solutions. 
films showed typical rugosity (Rq) of $26 \mathrm{~nm}$ for copolymer P1 and $7 \mathrm{~nm}$ for copolymer P2 (Figures 5(a) and 5(b)). Thus, the copolymer with higher content of functionalized thiophene and 3-hexyl group has the largest value of rugosity; this fact may be related to the higher solubility of octyl group than the hexyl group in organic solvents. On the other hand, films $(4 \mathrm{mg} / \mathrm{mL}$ in chloroform) made by spin coating technique (Figures $5\left(\mathrm{a}^{\prime}\right)$ and $5\left(\mathrm{~b}^{\prime}\right)$ ) present a rugosity (Rq) of $17 \mathrm{~nm}$ for copolymer P1 and $16 \mathrm{~nm}$ for copolymer P2. The films made from chloroform solution by spin coating technique are more homogeneous for P1 because the more regular distribution was achieved with this technique. It must be observed that sometimes the conformation of the films is a partially ordered structure influenced by the molecular structure and the utilized solvent during film preparation [45]. Morphology of the films and the interaction between polymer chains can in turn alter (enhance or decrease) the NLO optical properties. It can be examined in a first approximation through the position of the absorption bands and its comparison with those exhibited in solution. For instance, the absorption spectrum in solid films $\left(\lambda_{\max }=\right.$ $493 \mathrm{~nm}$ ) is notoriously broader and red-shifted with respect to solution $\left(\lambda_{\max }=432 \mathrm{~nm}\right)$. Since the bands are associated with $\pi \rightarrow \pi^{*}$ electronic transitions the shift to longer wavelengths is associated with a reduced energy band gap, which can be traduced in enhanced nonlinear response.

3.2. Nonlinear Optical Properties. The choice of using THG technique to measure $\chi^{(3)}$ is because it allows measuring pure electronic NLO effects (important for high band width photonic applications). As an example of these experiments, Figure 6 shows the so-called THG Maker-Fringe pattern for thin films of the polymers P1 and P2. As reference, the figure also includes the THG pattern measured from the fused silica substrate alone (thickness: $1 \mathrm{~mm}$ ). Since these data were obtained at the near infrared wavelength of $1300 \mathrm{~nm}$, it follows that the THG signal is at $433 \mathrm{~nm}$. THG signals from P1 and P2 films are clearly discernable of the signal produced from the substrate alone, being nearly twenty and forty times stronger, respectively. From these data the calculated thirdorder nonlinear susceptibilities $\left(\chi^{(3)}\right)$ resulted to be 6.7 and $3.2\left(\times 10^{-12} \mathrm{esu}\right)$ for P1 and P2, respectively.

The polymer P1 with higher incorporation of functionalized monomer has the bigger value of $\chi^{(3)}$, and also this property is related with the conjugated backbone of the polymers, that is to say with their molecular weight. THG technique has the advantage of measuring nonlinearities of pure electronic origin; however, very few examples are found in the literature on the use of this technique to measure $\chi^{(3)}$ in PT. For instance, the technique was used in polythiophene azines, which exhibited a $\chi^{(3)}$ value of $5.4 \times 10^{-11}$ esu at $1550 \mathrm{~nm}$ [42]. This value is larger than the one we observed for P1 and P2; however, it must be noticed that the wavelength of $1550 \mathrm{~nm}$ ( $5 \mathrm{~ns}$ pulses) induced three-photon resonant effect enhancement (the maximum absorption of polymer coincided with the THG wavelength). Likewise, a maximum resonant $\chi^{(3)}$ value of $2 \times 10^{-11}$ esu for other classes of PT

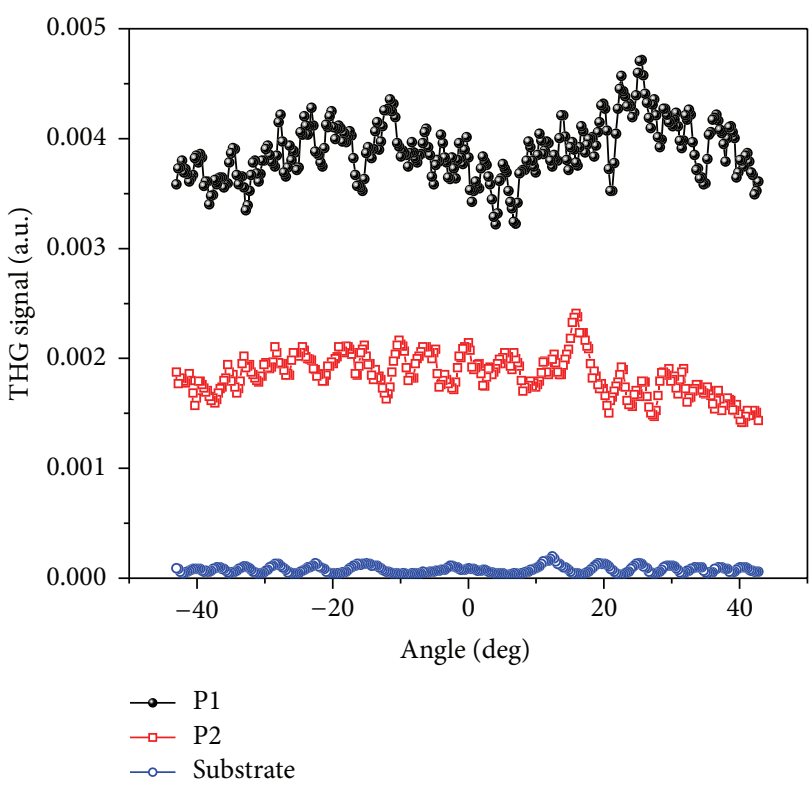

FIGURE 6: THG Maker-Fringe pattern from thin films $(433 \mathrm{~nm})$ of copolymers $\mathrm{P} 1$ and $\mathrm{P} 2$ deposited in a $1 \mathrm{~mm}$ thick glass substrate. As reference, the figure includes the THG signal from a subtrate without a film deposited on it.

derivatives was measured with THG experiments at $2100 \mathrm{~nm}$ [43] in which the dispersion of $\chi^{(3)}$ (plotted as a function of the THG wavelength) follows the linear absorption spectrum. In our case, the wavelength of THG is at $433 \mathrm{~nm}$ with the maximum of absorption of the tested solid film at $493 \mathrm{~nm}$, so the nonlinear response is partially resonantly enhanced. On the other hand, for push-pull side chain azobenzene polymer tested at $1064 \mathrm{~nm} \chi^{(3)}$ was $1.7 \times 10^{-11}$ esu [36] which is comparable to the value obtained for P1.

$\sigma_{2 \mathrm{PA}}$ values of P1 and $\mathrm{P} 2$ were evaluated in solutions. In particular, we determine the nonlinear effect at $800 \mathrm{~nm}$ by using fs pulses, a wavelength at which these copolymers are basically transparent; that is, their lineal absorption due to one-photon excitations is negligible. Figure 7 shows the open-aperture $Z$-scan curves for these copolymers in chloroform at the concentration of $3 \times 10^{-3} \mathrm{M}$ and laser peak intensity at the focal region of $22 \mathrm{GW} / \mathrm{cm}^{2}$. From this figure it is observed that the copolymers exhibit notorious nonlinear absorption, with somewhat more intense effect in P1 with respect to P2. Owing to the type of excitation (femtosecond pulses far from the linear absorption band) it is then recognized that the origin of the observed nonlinear absorption in these compounds is due to the instantaneous two-photon absorption process. Notice that the implementation of $Z$ scan technique with ultrashort optical excitation precludes the observation of other types of effects such as nonlinear absorption due to excited state absorption [32]. By fitting data to (2), it was found that the nonlinear absorption coefficients $\beta$ for the copolymer P1 and P2 are $-0.63 \mathrm{~cm} / \mathrm{GW}$ and $-0.54 \mathrm{~cm} / \mathrm{GW}$, respectively. Thus, the corresponding values of $\sigma_{2 \mathrm{PA}}$ resulted to be $8545 \mathrm{GM}$ and $6920 \mathrm{GM}$ considering the whole chain of copolymers, but with values of $233 \mathrm{GM}$ 
TABLE 2: Comparative analysis of $\chi^{(3)}$ value obtained by THG and $\sigma_{2 \mathrm{PA}}$ or $\beta$ values obtained by $Z$-scan technique.

\begin{tabular}{|c|c|c|c|}
\hline Polymers & $\begin{array}{c}\chi^{(3)}(-3 \omega, \omega, \omega, \omega) \text { measured } \\
\text { through THG }\end{array}$ & $\sigma_{2 \mathrm{PA}}$ or $\beta$ by $Z$-scan & Reference \\
\hline Poly(thiophene azines) & $\begin{array}{c}5.4 \times 10^{-11} \text { esu at } 1550 \mathrm{~nm} \\
(5 \mathrm{~ns} \text { pulses })\end{array}$ & & {$[42]$} \\
\hline Polythiophene derivative & $\begin{array}{c}2 \times 10^{-11} \text { esu at } 2100 \mathrm{~nm} \\
(4 \mathrm{~ns} \text { pulses })\end{array}$ & & {$[43]$} \\
\hline Push-pull azobenzene polymers & $\begin{array}{c}1.7 \times 10^{-11} \text { esu at } 1064 \mathrm{~nm} \\
(30 \mathrm{ps} \text { pulses })\end{array}$ & & {$[36]$} \\
\hline Regioregular P3HT & & $\begin{array}{c}\sigma_{2 \mathrm{PA}}=300 \mathrm{GM} \\
\text { (per repeated unit) at } 800 \mathrm{~nm} \\
(\text { fs pulses) }\end{array}$ & [32] \\
\hline Azopolymer derived RD1 & & $\begin{array}{c}\beta=-60.1 \mathrm{~cm} / \mathrm{GW} \text { at } 532 \mathrm{~nm} \\
\text { (ps pulses) }\end{array}$ & {$[37]$} \\
\hline Polyoxadiazoles & & $\begin{array}{c}\beta=-19.96 \mathrm{~cm} / \mathrm{GW} \text { at } 532 \mathrm{~nm} \\
\text { (ps pulses) }\end{array}$ & {$[44]$} \\
\hline P1 & $\begin{array}{c}6.7 \times 10^{-12} \text { esu at } 1300 \mathrm{~nm} \\
(8 \mathrm{~ns} \text { pulses })\end{array}$ & $\begin{array}{c}\beta=-0.63 \mathrm{~cm} / \mathrm{GW}, \sigma_{2 \mathrm{PA}}=233 \mathrm{GM} \\
(\text { per repeated unit) at } 800 \mathrm{~nm} \\
\text { (fs pulses) }\end{array}$ & This work \\
\hline $\mathrm{P} 2$ & $\begin{array}{l}3.1 \times 10^{-12} \text { esu at } 1300 \mathrm{~nm} \\
\quad(8 \mathrm{~ns} \text { pulses })\end{array}$ & $\begin{array}{c}\beta=-0.54 \mathrm{~cm} / \mathrm{GW}, \sigma_{2 \mathrm{PA}}=194 \mathrm{GM} \\
(\text { per repeated unit) at } 800 \mathrm{~nm} \\
\text { (fs pulses) }\end{array}$ & This work \\
\hline
\end{tabular}

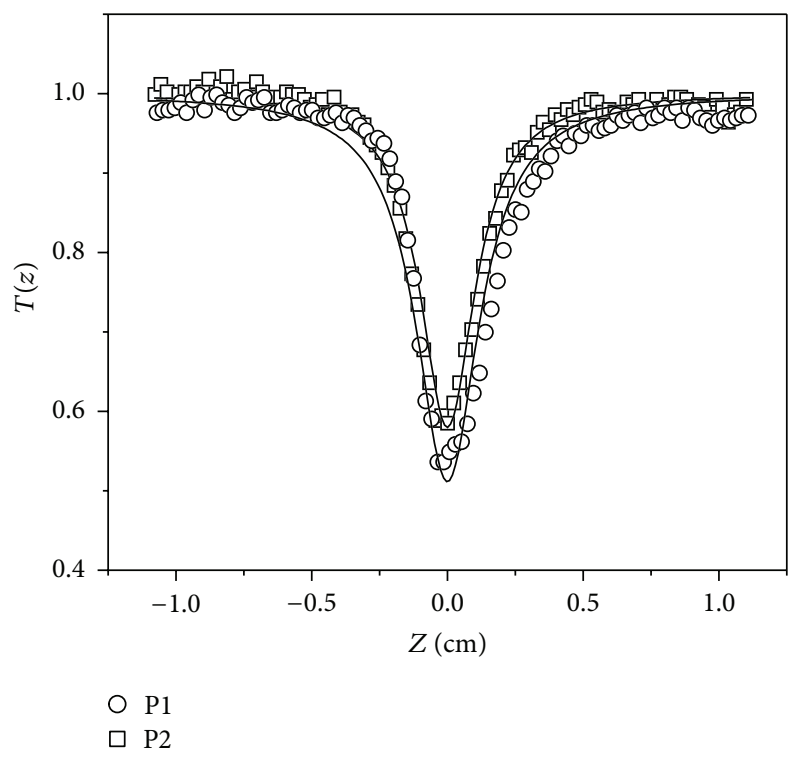

FIgURE 7: Open-aperture $Z$-scan measurements for solutions of copolymers $\mathrm{P} 1$ and $\mathrm{P} 2\left(3 \times 10^{-3} \mathrm{M}\right)$ in chloroform under femtosecond excitation $(800 \mathrm{~nm})$ with peak intensity of $22 \mathrm{GW} / \mathrm{cm}^{2}$.

and 194 GM per repeated basic monomeric unit. Notoriously, this value is very close to the value of $300 \mathrm{GM}$ (per repeated unit) measured in the regioregular poly(3-hexylthiophene) (P3HT) at the same wavelength $(800 \mathrm{~nm})$ in diluted solution in chloroform [32]. It means that even though P1 and P2 are not regioregular polymers, their NLO properties resulted practically the same that the one observed in P3HT. In this study reported by Szeremeta et al. [32], the regioregular P3HT commercially available from Sigma-Aldrich was of electronic grade, with diads configuration > 95\% and $\mathrm{Mn}=15000-4500 \mathrm{Da}, \mathrm{PDI} \leq 2$. The solution spectrum of regioregular p3HT shows a broad peak with $\lambda_{\max }=420 \mathrm{~nm}$ in chloroform whereas the main peak in the film spectrum, assigned to transitions from HOMO to LUMO, is at $\lambda_{\max }=$ $520 \mathrm{~nm}$ [32] while in our case the copolymer P1 has $\overline{\mathrm{Mn}}=$ $6908 \mathrm{Da}, \mathrm{PDI}=3.8$ with diads configuration of $74 \%$. The absorption spectrum showed a broad peak at $\lambda_{\max }=430 \mathrm{~nm}$ in THF and the film spectrum a $\lambda_{\max }=495 \mathrm{~nm}$ in the film spectrum. Notice that in this work we focused on measuring the magnitude of the nonlinear absorption $\left(\beta\right.$ and $\left.\sigma_{2 \mathrm{PA}}\right)$ at a wavelength $(800 \mathrm{~nm})$ relatively far from the single photon absorption; that is, the edge absorption wavelength for P1 and P2 is at ca $550 \mathrm{~nm}$. In contrast, other authors have tested PT near or at wavelengths where the nonlinear absorption is assisted by single photon transitions; that is, in these cases the nonlinear effects are not necessarily due to instantaneous two-photon absorption process, as in our case. For instance, Udayakumar et al. [44] tested copolymers containing 3,4dialkoxythiophene and (1,3,4-oxadiazolyl) benzene units at $532 \mathrm{~nm}$ using nanosecond pulses, obtaining values of nonlinear coefficients $\beta$ of -14.52 and $-19.9 \mathrm{~cm} / \mathrm{GW}$. In the case of RD1-containing side chain methyl methacrylate polymer has a nonlinear absorption coefficient of $\beta=-60.1 \mathrm{~cm} / \mathrm{GW}$ values using the $Z$-scan technique ( $35 \mathrm{ps}$ and $532 \mathrm{~nm}$ ) [37]. Table 2 summarizes a comparison of the values of the third-order nonlinear susceptibility $\chi^{(3)}$ and the nonlinear absorption parameters $\left(\sigma_{2 \mathrm{PA}}\right.$ or $\left.\beta\right)$ of $\mathrm{P} 1$ and $\mathrm{P} 2$ with other $\mathrm{PT}$ or azobenzene polymers reported recently in the literature.

\section{Conclusions}

New polythiophenes derived from 3-alkylthiophenes and a thiophene substituted with DR19 were synthesized by an easy and cost-effective procedure. Their physicochemical 
characterization showed similar values of thermal stability (around $\left.480^{\circ} \mathrm{C}\right)$, molecular weight $(\mathrm{Mn} \sim 7000$, P1 has higher polydispersity than $\mathrm{P} 2$ ), and regioregularity (HT diads $75 \%$ ). These copolymers had a low incorporation (not more than 5\%, P1 > P2) of push-pull chromophore, disperse red 19. Nevertheless, films of these copolymers present significant third-order nonlinear susceptibility, which is related to the size of its conjugated backbone and the amount of incorporation of the functionalized thiophene. In particular, the third-order nonlinear susceptibility in solid films exhibited a maximum value of $6.7 \times 10^{-12} \mathrm{esu}$ at $1300 \mathrm{~nm}$ and it was affected by the molecular structure, that is, the difference of TDR19 incorporation and the length of the chains of the 3alkylthiophenes in the copolymers. In solution the $\sigma_{2 \mathrm{PA}}$ values at infrared wavelengths of our polythiophenes were similar to the regioregular ones.

\section{Conflict of Interests}

The authors declare that there is no conflict of interests regarding the publication of this paper.

\section{Acknowledgments}

Authors would like to thank CIQ-UAEM for spectroscopic analysis and the Laboratory of Ultrafast Optics at the Centro de Investigaciones en Óptica for the facilities provided for this work. This work was funded by PROMEP/103.5/07/2674 and CONACYT (Grants CB2007-81383-Q and 132946), M. Chávez-Castillo acknowledges CONACYT for scholarship.

\section{References}

[1] N. K. Jangid, N. P. S. Chauhan, K. Meghwal, R. Ameta, and P. B. Punjabi, "A review: conducting polymers and their applications," Research Journal of Pharmaceutical, Biological and Chemical Sciences, vol. 5, no. 3, pp. 383-412, 2014.

[2] R. Holze and Y. P. Wu, "Intrinsically conducting polymers in electrochemical energy technology: trends and progress," Electrochimica Acta, vol. 122, pp. 93-107, 2014.

[3] H.-J. Jhuo, P.-N. Yeh, S.-H. Liao, Y.-L. Li, Y.-S. Cheng, and S.-A. Chen, "Review on the recent progress in low band gap conjugated polymers for bulk hetero-junction polymer solar cells," Journal of the Chinese Chemical Society, vol. 61, no. 1, pp. 115-126, 2014.

[4] P. Sista, K. Ghosh, J. S. Martinez, and R. C. Rocha, "Polythiophenes in biological applications," Journal of Nanoscience and Nanotechnology, vol. 14, no. 1, pp. 250-272, 2014.

[5] V. C. Gonçalves and D. T. Balogh, "Optical chemical sensors using polythiophene derivatives as active layer for detection of volatile organic compounds," Sensors and Actuators, B: Chemical, vol. 162, no. 1, pp. 307-312, 2012.

[6] M. Liu, C. Luo, and H. Peng, "Electrochemical DNA sensor based on methylene blue functionalized polythiophene as a hybridization indicator," Talanta, vol. 88, pp. 216-221, 2012.

[7] H. Kim, S. Nam, J. Jeong et al., "Organic solar cells based on conjugated polymers: history and recent advances," Korean Journal of Chemical Engineering, vol. 31, no. 7, pp. 1095-1104, 2014.
[8] D. Minoli, Nanotechnology Applications to Telecommunications and Networking, Wiley-Interscience, John Wiley \& Sons, Hoboken, NJ, USA, 2006.

[9] M. Lee, H. E. Katz, Ch. Erben et al., "Broadband modulation of light by using an electro-optic polymer," Science, vol. 298, no. 5597, pp. 1401-1403, 2002.

[10] M. Shao, Y. He, K. Hong, C. M. Rouleau, D. B. Geohegan, and K. Xiao, "A water-soluble polythiophene for organic field-effect transistors," Polymer Chemistry, vol. 4, no. 20, pp. 5270-5274, 2013.

[11] S. K. Ahn, T. Ban, P. Sakthivel, S.-H. Jin, Y.-S. Gal, and J. H. Lee, "Synthesis and characterization of novel crosslinkable poly(propylene-dioxythiophene) derivative as a buffer layer for organic light-emitting diode applications," Macromolecular Research, vol. 20, no. 5, pp. 459-464, 2012.

[12] D. Sahoo, K. Sugiyasu, Y. Tian, M. Takeuchi, and I. G. Scheblykin, "Effect of conjugated backbone protection on intrinsic and light-induced fluorescence quenching in polythiophenes," Chemistry of Materials, vol. 26, no. 16, pp. 4867-4875, 2014.

[13] S. D. Bearden, J. P. Cannon, and S. A. Gold, "Spectroscopic and electrical evaluation of poly(3-hexylthiophene) nanotubules made using template wetting nanofabrication," Synthetic Metals, vol. 160, no. 19-20, pp. 2045-2050, 2010.

[14] K. P. R. Nilsson and P. Hammarström, "Luminescent conjugated polymers: illuminating the dark matters of biology and pathology," Advanced Materials, vol. 20, no. 13, pp. 2639-2645, 2008.

[15] M. Zagórska, I. Kulszewicz-Bajer, A. Proń et al., "Preparation and spectroscopic and spectroelectrochemical characterization of copolymers of 3-alkylthiophenes and thiophene functionalized with an azo chromophore," Macromolecules, vol. 31, no. 26, pp. 9146-9153, 1998.

[16] M. Zagorska, I. Kulszewicz-Bajer, A. Pron, P. Raimond, F. Kajzar, and A.-J. Attias, "Polythiophenes functionalized with disperse red 1 chromophore," Synthetic Metals, vol. 102, no. 13, pp. 1141-1142, 1999.

[17] C. Della-Casa, A. Fraleoni, P. Costa-Bizzarri, and M. Lanzi, "New 3-alkylthiophene copolymers functionalized with a NLO chromophore," Synthetic Metals, vol. 124, no. 2-3, pp. 467-470, 2001.

[18] M. Lanzi, L. Paganin, P. Costa-Bizzarri, C. Della-Casa, and A. Fraleoni, "Facile synthesis of soluble multifunctional polyalkylthiophenes," Macromolecular Rapid Communications, vol. 23, no. 10-11, pp. 630-633, 2002.

[19] C. Della-Casa, P. Costa-Bizzarri, M. Lanzi et al., "Monomers of 3-alkyl-substituted thiophene: synthetic routes for the functionalization with non-linear optical chromophores," Synthetic Metals, vol. 138, no. 3, pp. 409-417, 2003.

[20] M. Lanzi, L. Paganin, and P. Costa-Bizzarri, "Synthesis and polymerization of a new thiophene functionalized with both NLO-active chromophore and an alkylic self-plastifying chain," European Polymer Journal, vol. 40, no. 9, pp. 2117-2127, 2004.

[21] C. Della-Casa, A. Fraleoni-Morgera, M. Lanzi et al., "Preparation and characterization of thiophene copolymers with second order non-linear optical properties," European Polymer Journal, vol. 41, no. 10, pp. 2360-2369, 2005.

[22] V. C. Gonçalves and D. T. Balogh, "Synthesis and characterization of a dye-functionalized polythiophene with different chromic properties," European Polymer Journal, vol. 42, no. 12, pp. 3303-3310, 2006.

[23] M. Lanzi, F. Bertinelli, L. Paganin, P. Costa-Bizzarri, and G. Cesari, "Electronic transitions of polyalkylthiophenes partially 
derivatized with NLO chromophores: a theoretical and experimental study," Macromolecular Chemistry and Physics, vol. 207, no. 14, pp. 1253-1261, 2006.

[24] U. Caruso, R. Diana, A. Fort, B. Panunzi, and A. Roviello, "Synthesis of polymers containing second order NLO-active thiophene and thiazole based chromophores," Macromolecular Symposia, vol. 234, pp. 87-93, 2006.

[25] R. M. F. Batista, S. P. G. Costa, M. Belsley, and M. M. M. Raposo, "Synthesis and second-order nonlinear optical properties of new chromophores containing benzimidazole, thiophene, and pyrrole heterocycles," Tetrahedron, vol. 63, no. 39, pp. 98429849, 2007.

[26] D. W. Kim, J. J. Choi, J.-S. Lim, and Ch. Lee, "Push-pull chromophore with phenylene and thiophene as conjugation bridge for electro-optic applications," Molecular Crystals and Liquid Crystals, vol. 463, no. 1, pp. 43/[325]-53/[335], 2007.

[27] X. Ma, R. Liang, F. Yang et al., "Synthesis and properties of novel second-order NLO chromophores containing pyrrole as an auxiliary electron donor," Journal of Materials Chemistry, vol. 18, no. 15, pp. 1756-1764, 2008.

[28] Z. Shi, X. Zhang, and Z. Cui, "Synthesis and characterization of thiophene-containing chromophores for nonlinear optical (NLO) materials," Journal of Nonlinear Optical Physics \& Materials, vol. 17, no. 3, pp. 243-254, 2008.

[29] B.-Z. Zhang and X.-Y. Zhao, "Synthesis, characterization, and photochromic behaviors of polythiophene derivatives in the solid state," Journal of Materials Science, vol. 44, no. 11, pp. 27652773, 2009.

[30] M. E. Nicho, S. García-Carvajal, P. A. Márquez-Aguilar, M. Güizado-Rodríguez, J. Escalante-García, and G. MedranoBaca, "Synthesis and physicochemical characterization of copolymers of 3-octylthiophene and thiophene functionalized with azo chromophore," Materials Chemistry and Physics, vol. 129, no. 3, pp. 1027-1034, 2011.

[31] T. Kobayashi, W. Shinke, T. Nagase, S. Murakami, and H. Naito, "Third-order optical susceptibility in polythiophene thin films prepared by spin-coating from high-boiling-point solvents," Thin Solid Films, vol. 554, pp. 106-109, 2014.

[32] J. Szeremeta, R. Kolkowski, M. Nyk, and M. Samoc, "Wavelength dependence of the complex third-order nonlinear optical susceptibility of poly(3-hexylthiophene) studied by femtosecond z-scan in solution and thin film," Journal of Physical Chemistry C, vol. 117, no. 49, pp. 26197-26203, 2013.

[33] H. Ishitobi, Z. Sekkat, and S. Kawata, "Ordering of azobenzenes by two-photon isomerization," The Journal of Chemical Physics, vol. 125, no. 16, Article ID 164718, 2006.

[34] R. Czaplicki, O. Krupka, Z. Essaïdi et al., "Grating inscription in picosecond regime in thin films of functionalized DNA," Optics Express, vol. 15, no. 23, pp. 15268-15273, 2007.

[35] S. Kawata and Y. Kawata, "Three-dimensional optical data storage using photochromic materials," Chemical Reviews, vol. 100, no. 5, pp. 1777-1788, 2000.

[36] H. El Ouazzani, K. Iliopoulos, M. Pranaitis et al., "Secondand third-order nonlinearities of novel push-pull azobenzene polymers," Journal of Physical Chemistry B, vol. 115, no. 9, pp. 1944-1949, 2011.

[37] I. Papagiannouli, K. Iliopoulos, D. Gindre et al., "Third-order nonlinear optical response of push-pull azobenzene polymers," Chemical Physics Letters, vol. 554, pp. 107-112, 2012.

[38] C. Samyn, T. Verbiest, and A. Persoons, "Second-order nonlinear optical polymers," Macromolecular Rapid Communications, vol. 21, no. 1, pp. 1-15, 2000.
[39] K. Fedus, V. Smokal, O. Krupka, and G. Boudebs, "Synthesis and non-resonant nonlinear optical properties of push-pull side-chain azobenzene polymers," Journal of Nonlinear Optical Physics and Materials, vol. 20, no. 1, pp. 1-13, 2011.

[40] N. Liaros, S. Couris, L. Maggini et al., "NLO response of photoswitchable azobenzene-based materials," ChemPhysChem, vol. 14, no. 13, pp. 2961-2972, 2013.

[41] F. X. Qiu, D. Y. Yang, P. P. Li, and X. Wang, "Preparation and third-order nonlinear optical property of poly(urethane-imide) containing dispersed red chromophore," Express Polymer Letters, vol. 2, no. 11, pp. 823-828, 2008.

[42] A. Faccinetto, S. Mazzucato, D. Pedron, R. Bozio, S. Destri, and W. Porzio, "Non-resonant z-scan characterization of the third-order nonlinear optical properties of conjugated poly(thiophene azines)," Chemical Physics and Physical Chemistry, vol. 9, no. 14, pp. 2028-2034, 2008.

[43] E. van Keuren, V. Belov, H. Matsuda et al., "Nonlinear optical properties of a novel polythiophene derivative determined by third harmonic generation, Z-scan and degenerate four-wave mixing," Molecular Crystals and Liquid Crystals, vol. 315, pp. 373-384, 1998.

[44] D. Udayakumar, A. J. Kiran, A. V. Adhikari, K. Chandrasekharan, and H. D. Shashikala, "Synthesis and nonlinear optical characterization of copolymers containing alternating 3,4dialkoxythiophene and (1,3,4-oxadiazolyl) benzene units," Journal of Applied Polymer Science, vol. 106, no. 5, pp. 3033-3039, 2007.

[45] H. G. Kuzyk and C. W. Dirk, Eds., Characterization Techniques and Tabulations for Organic Nonlinear Materials, Marcel Dekker, New York, NY, USA, 1998.

[46] S. Cook, A. Furube, and R. Katoh, "Analysis of the excited states of regioregular polythiophene P3HT," Energy and Environmental Science, vol. 1, no. 2, pp. 294-299, 2008.

[47] J. Brazard, R. J. Ono, C. W. Bielawski, P. F. Barbara, and D. A. V. Bout, "Mimicking conjugated polymer thin-film photophysics with a well-defined triblock copolymer in solution," The Journal of Physical Chemistry B, vol. 117, no. 16, pp. 4170-4176, 2013. 

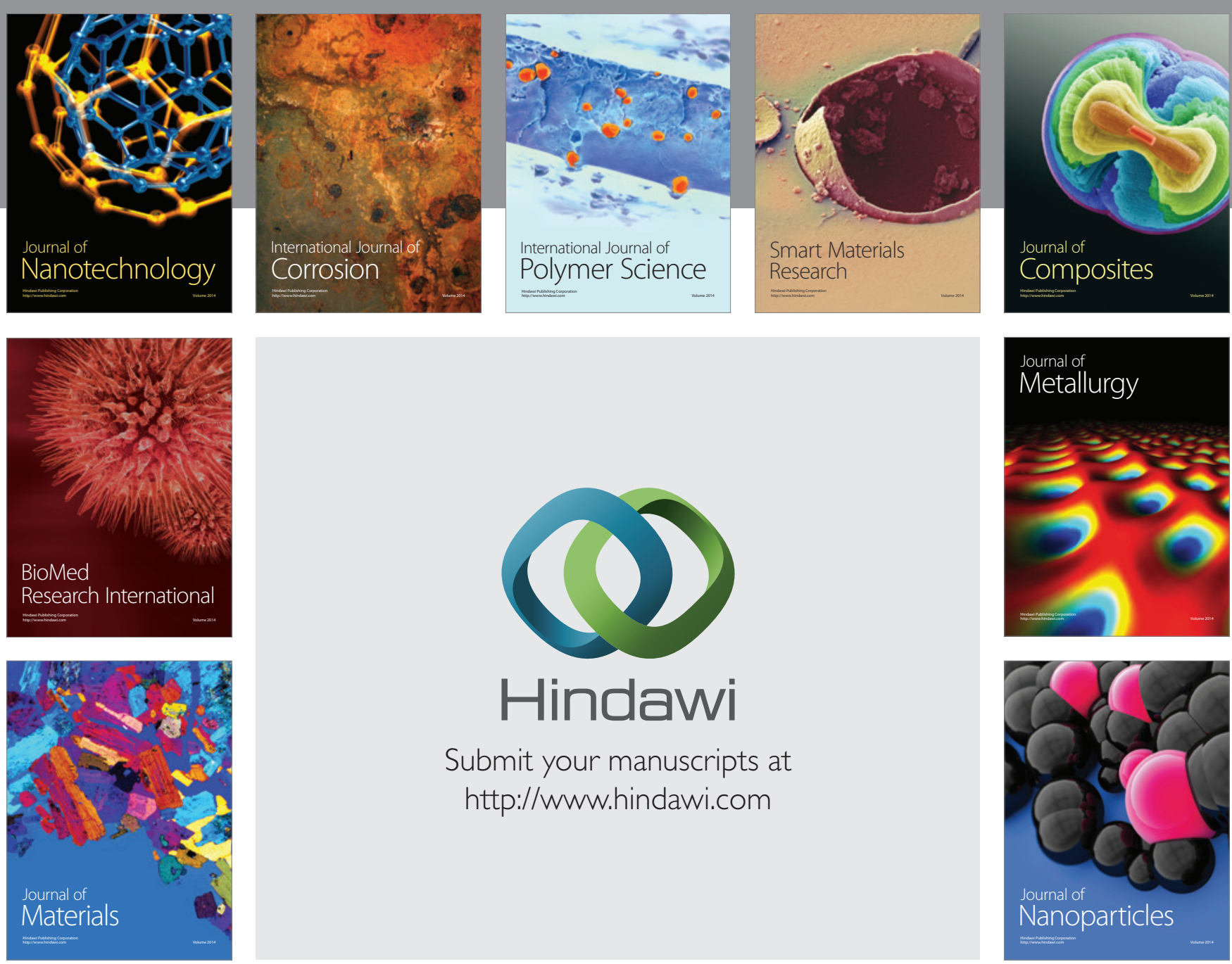

Submit your manuscripts at http://www.hindawi.com
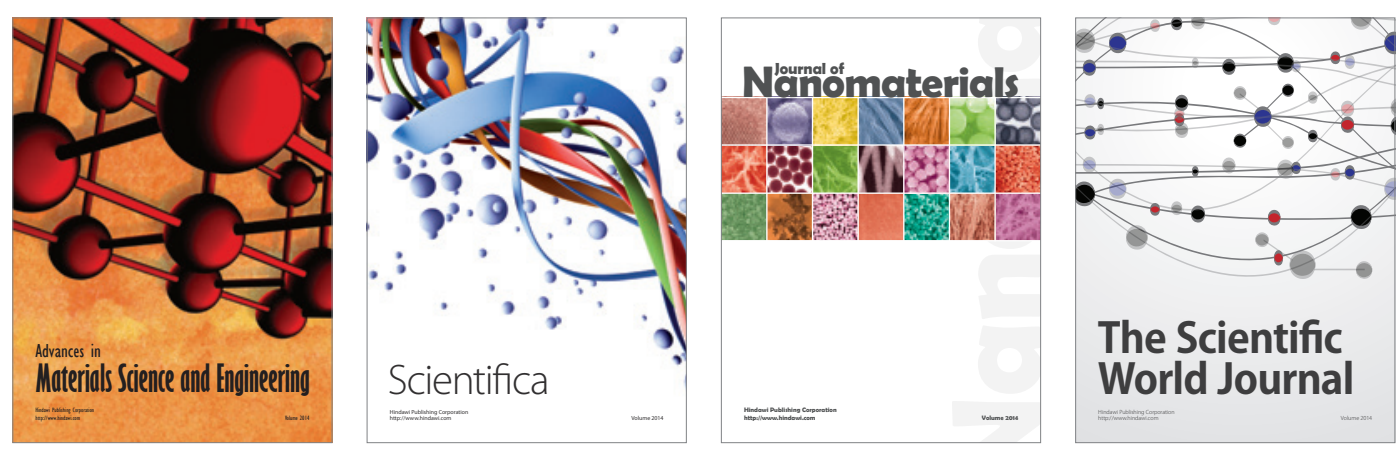

\section{The Scientific World Journal}
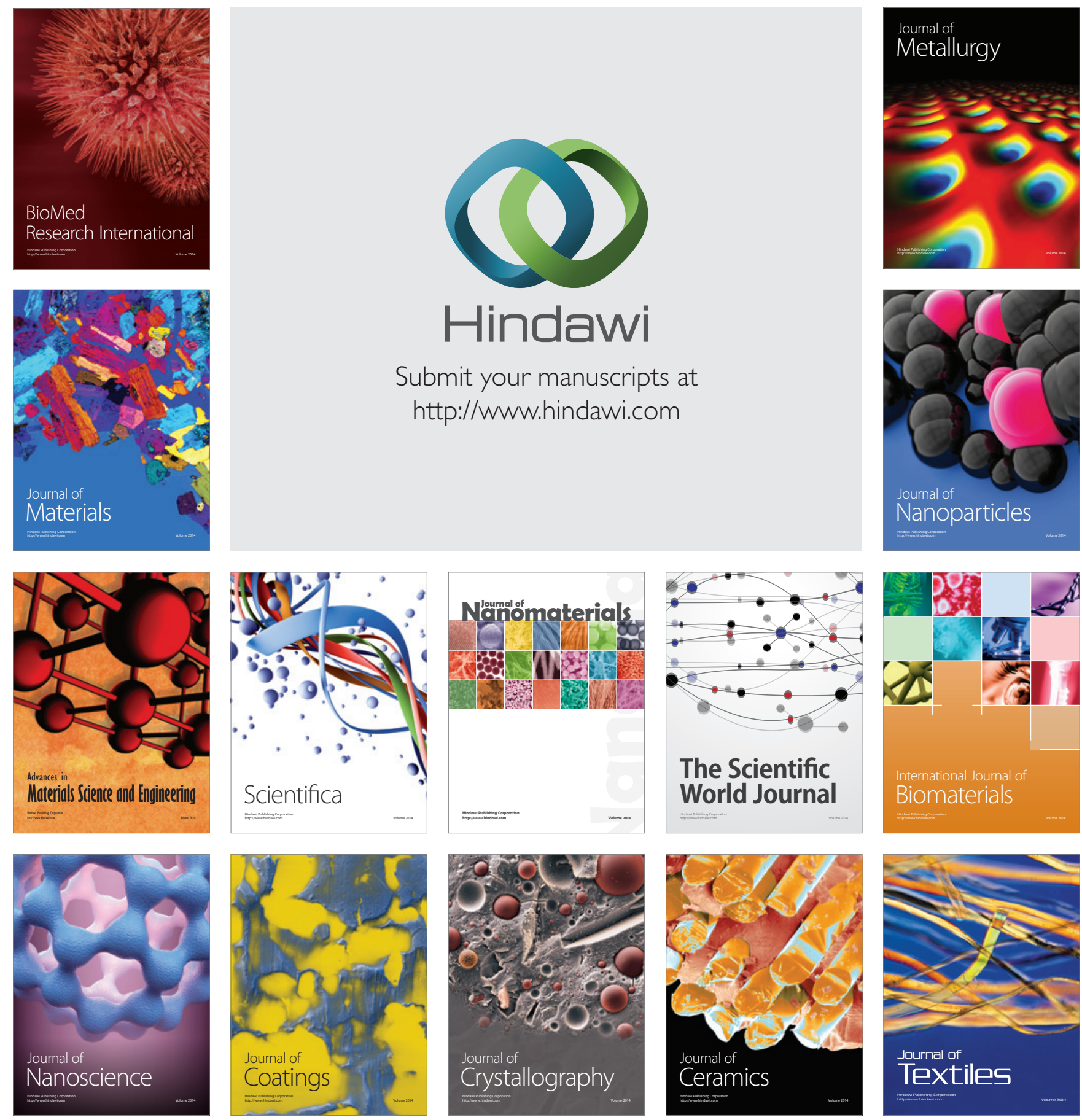